\title{
Reproductive biology of common carp (Cyprinus carpio Linnaeus, 1758) in Lake Hayq, Ethiopia
}

\author{
Assefa Tessema1* (D), Abebe Getahun', Seyoum Mengistou', Tadesse Fetahi' and Eshete Dejen²
}

\begin{abstract}
This study was conducted in Lake Hayq between January and December 2018. The objectives of this study were to determine the growth, condition, sex ratio, fecundity, length at first sexual maturity $\left(L_{50}\right)$, and spawning seasons of common carp (Cyprinus carpio). Monthly fish samples of $C$. carpio were collected using gillnets of stretched mesh sizes of $4,6,7,8,10$, and $13 \mathrm{~cm}$ and beach seines of mesh size of $6 \mathrm{~cm}$. Immediately after the fish were captured, total length (TL) and total weight (TW) for each individual were measured in centimeters and grams, respectively, and their relationship was determined using power function. Length at first maturity $\left(L_{50}\right)$ was determined for both males and females using the logistic regression model. The spawning season was determined from the frequency of mature gonads and variation of gonadosomatic index (GSI) values of both males and females. Fecundity was analyzed from 67 mature female specimens. The length and weight relationship of $C$. carpio was TW $=0.015 T L^{2.93}$ for females and TW $=$ $0.018 \mathrm{TL}^{2.87}$ for males that indicate negative allometric growth in both cases. The mean Fulton condition factor $\left(C_{\mathrm{F}}\right)$ was $1.23 \pm 0.013$ for females and $1.21 \pm 0.011$ for males. The value of $C_{F}$ in both cases was $>1$ that shows both sexes are in good condition. Among the total 1055 C. carpio collected from Lake Hayq, 459 (43.5\%) were females and 596 (56.5\%) were males. The chi-square test showed that there was a significant deviation between male and female numbers from 1:1 ratio $\left(X^{2}=22, \mathrm{df}=11, P>0.05\right)$ within sampling months. The length at first sexual maturity $\left(L_{50}\right)$ for females and males were 21.5 and $17.5 \mathrm{~cm}$, respectively. Males mature at smaller sizes than females. The spawning season of $C$. carpio was extended from February to April, and the peak spawning season for both sexes was in April. The average absolute fecundity was $28,100 \pm 17,462$. C. carpio is currently the commercially important fish while Nile tilapia fishery has declined in Lake Hayq. Therefore, this baseline data on growth, condition, and reproductive biology of common carp will be essential to understand the status of the population of carp and design appropriate management systems for the fish stock of Lake Hayq, Ethiopia, and adjacent countries.
\end{abstract}

Keywords: Growth, Fulton condition factor, Sex ratio, Length at first sexual maturity spawning seasons, Fecundity

\section{Introduction}

Common carp (Cyprinus carpio) is one of the widely cultured commercially important freshwater fish species in the world (FAO 2013). C. carpio is native to Eastern Europe and Central Asia. It can tolerate a wide range of water quality parameters. In natural water bodies, this

\footnotetext{
* Correspondence: atecklie2018@gmail.com

'Department of Zoological Sciences, Addis Ababa University, Addis Ababa, Ethiopia

Full list of author information is available at the end of the article
}

species can survive in very low water temperature and it can tolerate low concentrations and supersaturation of dissolved oxygen (Banarescu and Coad 1991).

Common carp is omnivorous fish species that consume animals (aquatic insects, macroinvertebrates, and zooplankton) and plant origin (phytoplankton, macrophytes) (Rahman et al. 2008, 2009; Weber and Brown 2009). C. carpio grows rapidly, achieves sexual maturation in the second year of life, and is highly fertile (about 2 million eggs per female) (Balon 1975; Hossain et al. 2016). The

(c) The Author(s). 2020 Open Access This article is licensed under a Creative Commons Attribution 4.0 International License, which permits use, sharing, adaptation, distribution and reproduction in any medium or format, as long as you give appropriate credit to the original author(s) and the source, provide a link to the Creative Commons licence, and indicate if changes were made. The images or other third party material in this article are included in the article's Creative Commons licence, unless indicated otherwise in a credit line to the material. If material is not included in the article's Creative Commons licence and your intended use is not permitted by statutory regulation or exceeds the permitted use, you will need to obtain permission directly from the copyright holder. To view a copy of this licence, visit http://creativecommons.org/licenses/by/4.0/. 
combination of these features allows developing invasiveness potential (Troca and Vieira 2012).

Knowledge of fish reproductive biology is very important for the rational utilization of fish stocks and their sustainable production (Cochrane 2002; Temesgen 2017). Understanding the reproductive aspects of fish is also very important for providing sound scientific advice in fishery management (Hossain et al. 2017; Khatun et al. 2019).

Common carp have been introduced into many water bodies throughout the world, including Europe, Australia, North America, Africa, and Asia. The wide distribution and successful introductions of common carp are mostly due to their tolerance to variable environmental conditions (Forester and Lawrence 1978), as well as to their capability for early sexual maturity and rapid growth (Koehn 2004).

Cyprinus carpio was first introduced to Aba Samuel Dam (Awash River basin) in 1940 from Italy (Getahun 2017). Later, C. carpio has been introduced in Lake Ziway in the late 1980s (FAO 1997; Abera et al. 2015), in highland lakes such as Ashengie, Ardibo, and Maybar (Golubtsov and Darkov 2008) for food security purpose, and the introduction was successful. Common carp were introduced to Lake Hayq accidentally from Lake Ardibo in 2008 (Wolde Mariam, Personal Communication 2018) through Ankerkeha River that connects the two lakes during the rainy season. Though common carp have established recently in Lake Hayq, it is dominating the other commercially important fish species, Nile tilapia and catfish. Fishermen of Lake Hayq believe that the current stunt growth of Nile tilapia (Oreochromis niloticus) is due to the recent invasion of common carp in the lake.

Though there are some research works conducted in different water bodies of Ethiopia on common carp reproductive biology such as Hailu (2013) in Amerti Reservoir, Abera (2015) in Lake Ziway, and Asnake (2010) in Lake Ardibo, there is no information on the reproductive biology of common carp in Lake Hayq. Therefore, the purpose of this study was to establish baseline data on growth and condition, sex ratio, fecundity, length at first sexual maturity, and spawning seasons of common carp and design management strategy for the population of common carp in Lake Hayq.

\section{Materials and methods}

\section{Study area and sampling techniques Study area}

The study was conducted in Lake Hayq. Lake Hayq is located in the North Central highlands of Ethiopia. It is a typical example of highland lake of Ethiopia with volcanic origin. Geographically, it lies between $11^{\circ} 3^{\prime} \mathrm{N}$ to $11^{\circ} 18^{\prime} \mathrm{N}$ latitude and $39^{\circ} 41^{\prime} \mathrm{E}$ to $39^{\circ} 68^{\prime} \mathrm{E}$ longitude with an average elevation of 1911 meters above sea level. The lake has a closed drainage system, and the total watershed area is about $77 \mathrm{~km}^{2}$ of which $22.8 \mathrm{~km}^{2}$ is occupied by Lake Hayq. According to Demlie et al. (2007), the average depth of the lake is $37 \mathrm{~m}$, and the maximum depth is $81 \mathrm{~m}$. The only stream entering the lake is the Ankerkeha River, which flows into its southeastern corner. According to Fetahi et al. (2011), Lake Hayq is classified as a small highland freshwater (Fig. 1).

\section{Climate}

Among the climate variables, only maximum and minimum temperature and rainfall of Lake Hayq were available at Kombolcha Meteorological Agency. In 2018, the average monthly maximum and minimum temperature around Lake Hayq was 25.9 and $9.9^{\circ} \mathrm{C}$, respectively (Fig. 2). The annual rainfall were $1200 \mathrm{~mm}$ (Fig. 3). The rainfall and the temperature variability around Lake Hayq for the last 10 years (2009-2018) were very low. The average monthly minimum and maximum temperature and annual rainfall were $9.8{ }^{\circ} \mathrm{C}, 26.6{ }^{\circ} \mathrm{C}$, and $1205.6 \mathrm{~mm}$, respectively (Kombolcha Meteorological Agency, 2019).

\section{Sampling techniques}

Fishery data Three sampling sites were selected based on the impact of human and livestock activities. These are littoral site with intensive human activities related to recreation in lodges; pelagic site, less impact from human and livestock; and river mouth (Ankerkeha River), carrying huge silt every year (Table 1). The sampling sites were fixed with GPS, and a map was generated (Fig. 1). Fish specimens were collected each month for 1 year using gill nets of 4, 6, 8, 10, and $13 \mathrm{~cm}$ stretched mesh sizes through setting the nets overnight in the lake and beach seines of 6 $\mathrm{cm}$ mesh size. Data such as length, weight, sex, and maturity stages were collected in the field immediately after the fish were caught.

\section{Some biological aspects of common carp Length-weight relationship}

The relationship between total length (TL) and total weight (TW) of C. carpio was calculated using power function as in Bagenal and Tesch (1978).

$$
\mathrm{TW}=\mathrm{aTL}^{\mathrm{b}}
$$

where

TW Total weight (g)

TL Total length $(\mathrm{cm})$

a Intercept of the regression line

b Slope of the regression line 


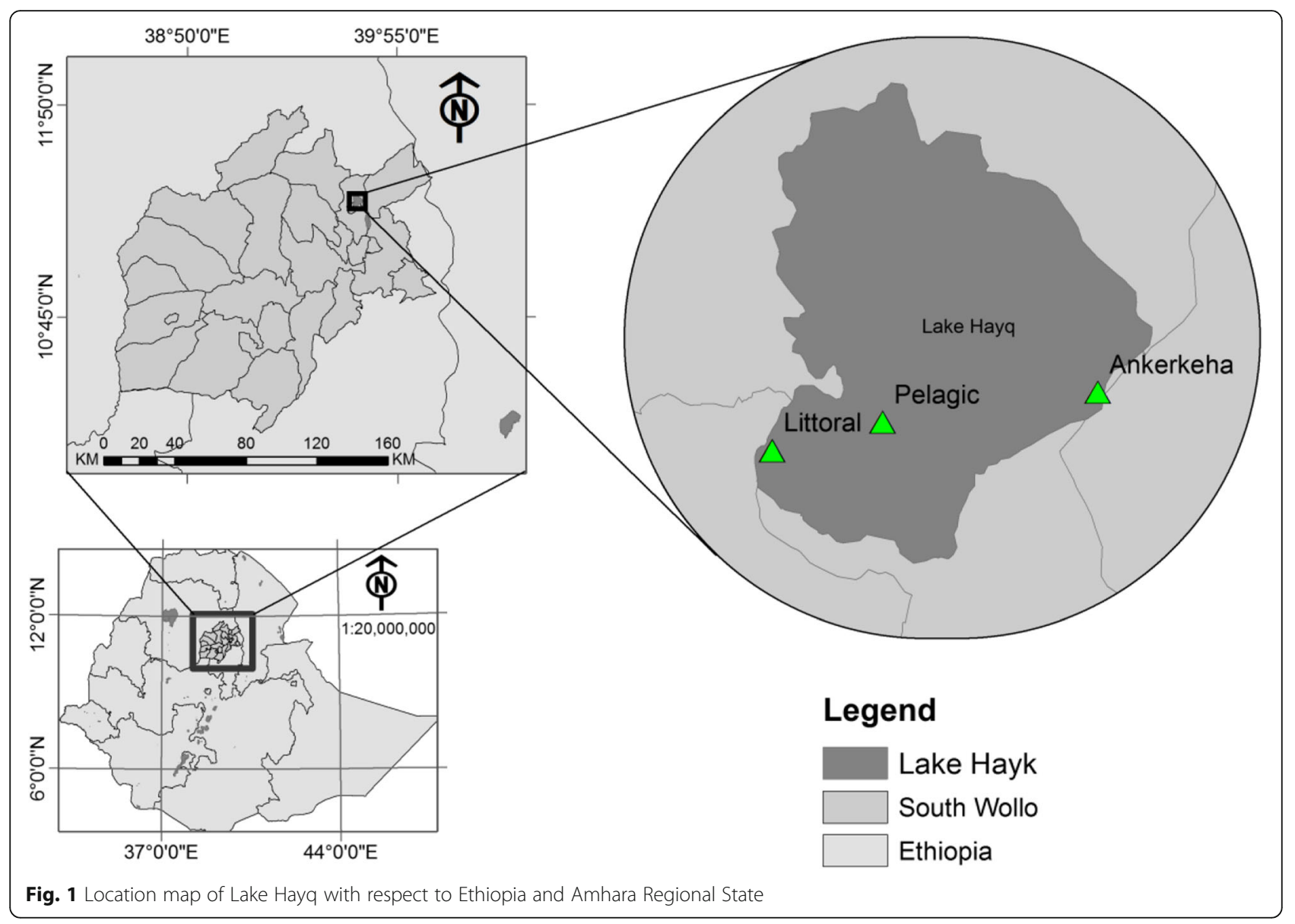

\section{Condition factor (Fulton factor)}

The wellbeing of common carp was determined by using the Fulton condition factor as indicated in Bagenal and Tesch (1978).

Fulton condition factor was calculated as:

$$
\mathrm{FCF}=\frac{\mathrm{TW}}{\mathrm{TL}^{3}} \times 100
$$

where TW is the total weight in grams and TL is the total length in centimeters

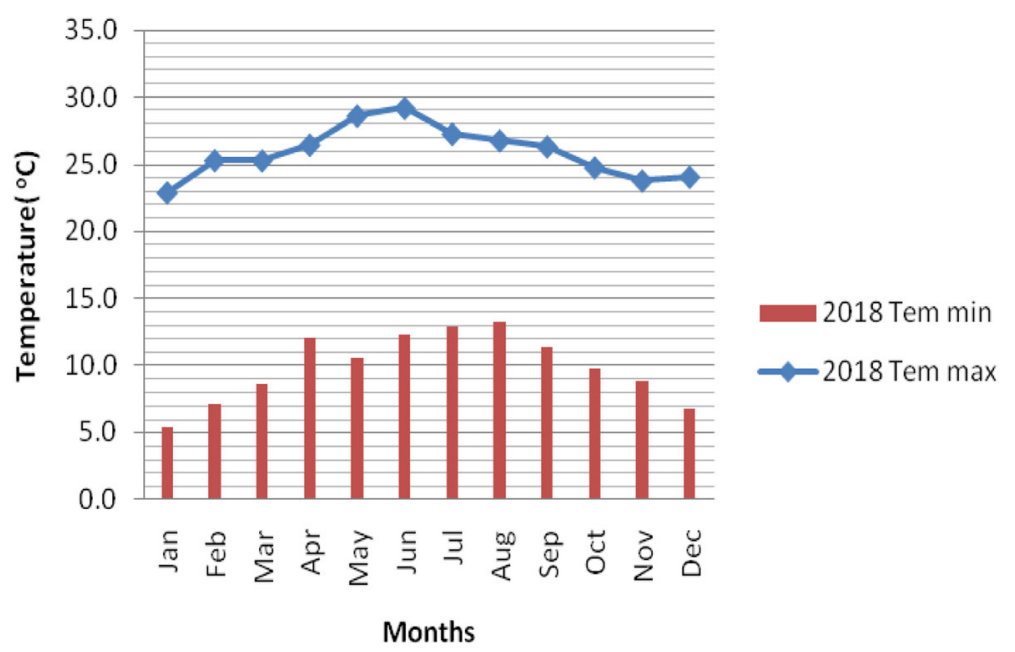

Fig. 2 Monthly maximum and minimum temperature variation of Lake Hayq in 2018 


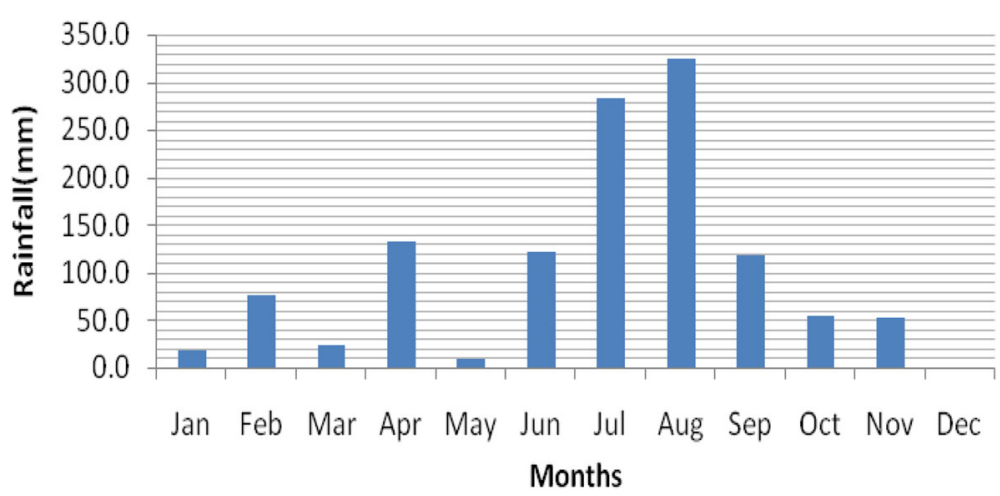

Fig. 3 Monthly rainfall variation of Lake Hayq in 2018

\section{Sex ratio}

Sex ratio was determined using the formula:

$$
\text { Sex ratio }=\frac{\text { Number of females }}{\text { Number of males }}
$$

\section{Fecundity}

The absolute fecundity (AF) of individual females was determined gravimetrically (Bagenal and Braum 1987), with the number of ripe oocytes counted from triplicates of 1-g sub-sample of the ovary. The relationship between absolute fecundity with total length, total weight, and gonad weight was determined using least squares regression.

\section{Spawning season}

The spawning season was determined from the percentages of fish with ripe gonads taken each month (Hossain and Ohtomi 2008) and from monthly GSI variations (Hossain et al. 2017). The spawning seasons of C. carpio were determined based on monthly variations of the gonadosomatic index (GSI):

$$
G S I=\frac{W_{g}}{W-W_{g}} \times 100
$$

where $W_{\mathrm{g}}$ is the gonad weight $(\mathrm{g})$ and $W$ is the total weight (g) of the fish (Ricker 1975).

\section{Maturity estimation}

Total length $(\mathrm{cm})$ and total weight $(\mathrm{g})$ of each specimen of common carp were measured at the sampling sites using measuring board and sensitive balance, respectively. After dissection, the gonad maturity of each specimen was identified using a 5-point maturity scale (Wudneh, 1998). The length at which $50 \%$ of both sexes reached maturity $\left(L_{50}\right)$ was determined from the percentages of mature fish selected from peak breeding seasons (March-April) and fitted to the logistic equation described by Echeverria (1987).

\section{Data analysis}

Descriptive statistics (frequency, percentages, and graphs) and inferential statistics (chi-square, independent $t$ test, linear, and logistic regression) were used to summarize the collected data. SPSS Software Package version 16 and R 3.3.1 were used to summarize the collected data.

\section{Results}

\section{Length-weight relationship}

The total length of female and male $C$. carpio ranged from 11 to $50 \mathrm{~cm}$ and 10.5 to $52 \mathrm{~cm}$, respectively, and the total weight of females and males ranged from 19 to $1697 \mathrm{~g}$ and 18 to $1378 \mathrm{~g}$, respectively. The length-weight relationship of both female and male $C$. carpio in Lake Hayq was curvilinear, and as a result, the line fitted to the data was described by the regression equation (Table 2). In this study, the " $b$ "

\begin{tabular}{|c|c|c|c|c|c|}
\hline \multirow[t]{2}{*}{ Sampling sites } & \multirow[t]{2}{*}{ Characteristics } & \multirow{2}{*}{$\begin{array}{l}\text { Depth } \\
\text { (m) }\end{array}$} & \multirow{2}{*}{$\begin{array}{l}\text { Altitude } \\
\text { (m) }\end{array}$} & \multicolumn{2}{|c|}{ Coordinate points (UTM) } \\
\hline & & & & $\bar{x}$ & $Y$ \\
\hline Ankerkeha River Mouth & Silt load & 5.3 & 1900 & 579715.383 & 1253117.123 \\
\hline Pelagic & Open water (less impact) & 55.4 & 1907 & 576688.51 & 1252693.02 \\
\hline Littoral & Near lodges (more pressure) & 6.3 & 1903 & 575131.78 & 1252295.8 \\
\hline
\end{tabular}

Table 1 Sampling site description 
Table 2 Length-weight relationship of C. carpio in Lake Hayq

\begin{tabular}{lllll}
\hline Sex & $n$ & Regression equation & $R^{2}$ & Sig. \\
\hline Female & 454 & TW $=0.015 \mathrm{TL}^{2.93}$ & 0.97 & 0.001 \\
Male & 589 & TW $=0.018 \mathrm{TL}^{2.87}$ & 0.98 & 0.05 \\
\hline
\end{tabular}

values of both female and male C. carpio were significantly different from 3, showing allometric growth (Figs. 4 and 5)

\section{Fulton's condition factor}

The Fulton condition factor values of female and male C. carpio ranged from 1 to 1.98 and 1 to 1.83 , respectively. The mean and SE values of FCF of females and males were $1.23 \pm 0.013$ and $1.21 \pm 0.011$, respectively. The independent $t$ test analysis showed that there was no significant difference $(P>0.05)$ in mean FCF between male and female $C$. carpio in Lake Hayq.

\section{Sex ratio}

From 1055 specimens of C. carpio collected from Lake Hayq, 459 (43.5\%) were females and 596 (56.5\%) were males. The chi-square test showed that there was a significant deviation between males and females from 1:1 ratio $\left(X^{2}=22, \mathrm{df}=11, P>0.05\right)$ within sampling months.

\section{Reproductive aspects of common carp Length at first sexual maturity}

Size at first maturity $\left(L_{50}\right)$ is the size at which $50 \%$ of the fish get matured for the first time. From the logistic regression model analyzed, male $C$. carpio matured at smaller size $(17.5 \mathrm{~cm})$ than female $(21.5 \mathrm{~cm})$ in Lake Hayq as shown in Fig. 6.

\section{The occurrence of mature males and females}

The number of mature males (stage 4 ) of C. carpio was higher than that of females during sampling months. The number of mature female and male specimens was higher from January to April. The highest number of mature females and males was observed from February to April (Fig. 7). The 10-year (2009-2018) meteorological data analysis showed that the average atmospheric temperature around Lake Hayq from February to April was $27.2{ }^{\circ} \mathrm{C}$. Rainfall distribution around Lake Hayq is bimodal. Rainfall was available in these months for the same year around the lake. This warm weather condition and rainfall availability might trigger the spawning of common carp in the lake.

\section{Fecundity}

Sixty-seven fully mature C. carpio with TL (21-49 $\mathrm{cm})$ and TW (104-1230 g) were selected for fecundity study. The average absolute fecundity (AF) was $28100 \pm 17462$. The relation between AF with TL, TW, and GW was linear (Figs. 8, 9, and 10). There was a significant relation in absolute fecundity with TL, TW, and GW $(P<0.05)$.

\section{Gonadosomatic index}

Cyprinus carpio in Lake Hayq has more than one peak spawning season starting from February to April. However, the highest peak spawning season for both sexes was in April (Fig. 11).

\section{Discussion}

This reproductive biological study of C. carpio in Lake Hayq is the first report which will be used as basic and baseline information. The result of the study helps to know the population status of the fish and design the possible strategies for sustainable utilization of fisheries of the lake.

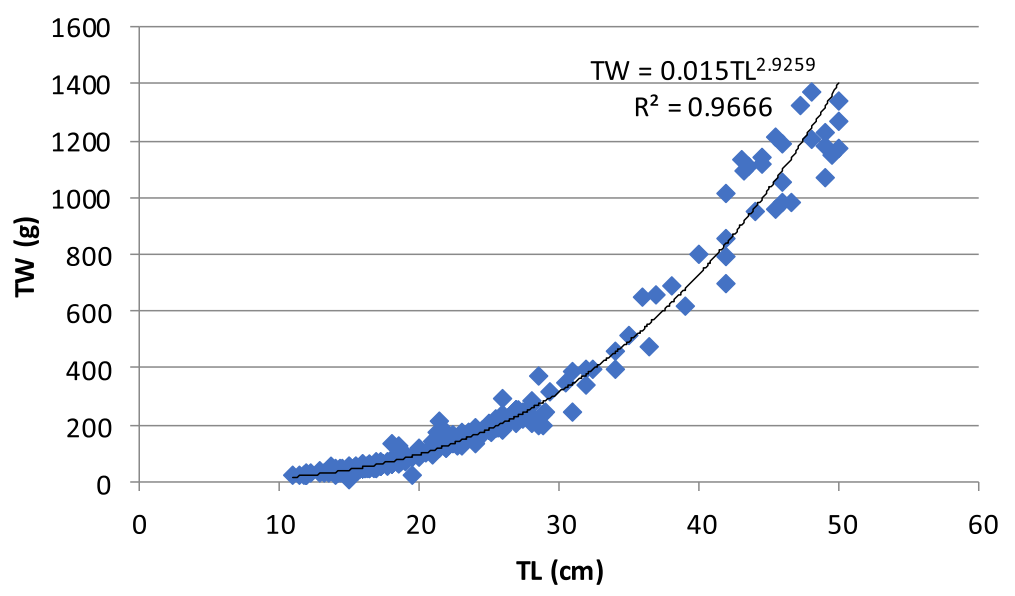

Fig. 4 Length-weight relationship of female Cyprinus carpio in Lake Hayq ( $N=459)$ 


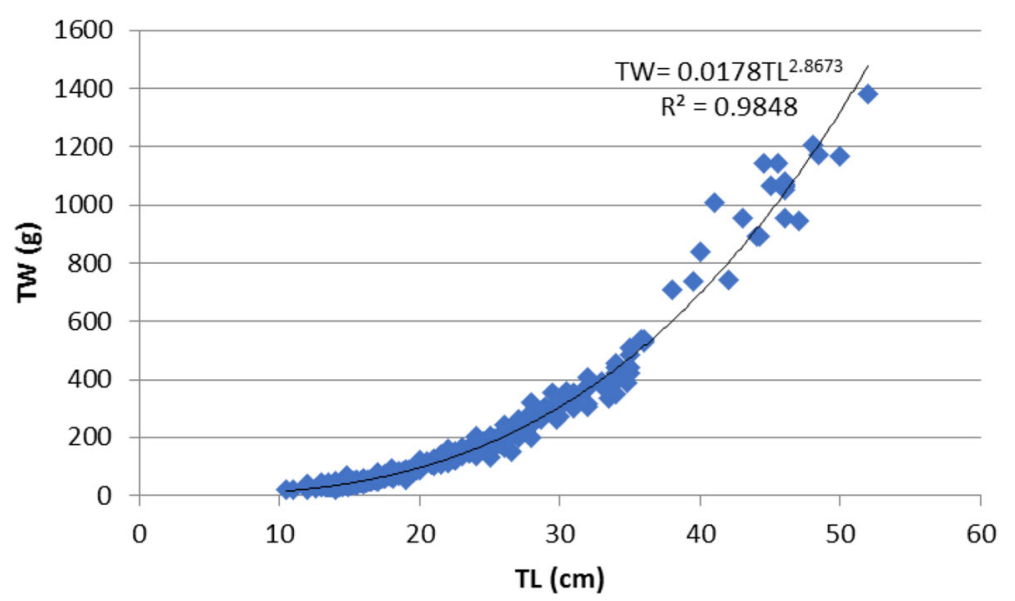

Fig. 5 Length-weight relationship of male Cyprinus carpio in Lake Hayq $(N=596)$
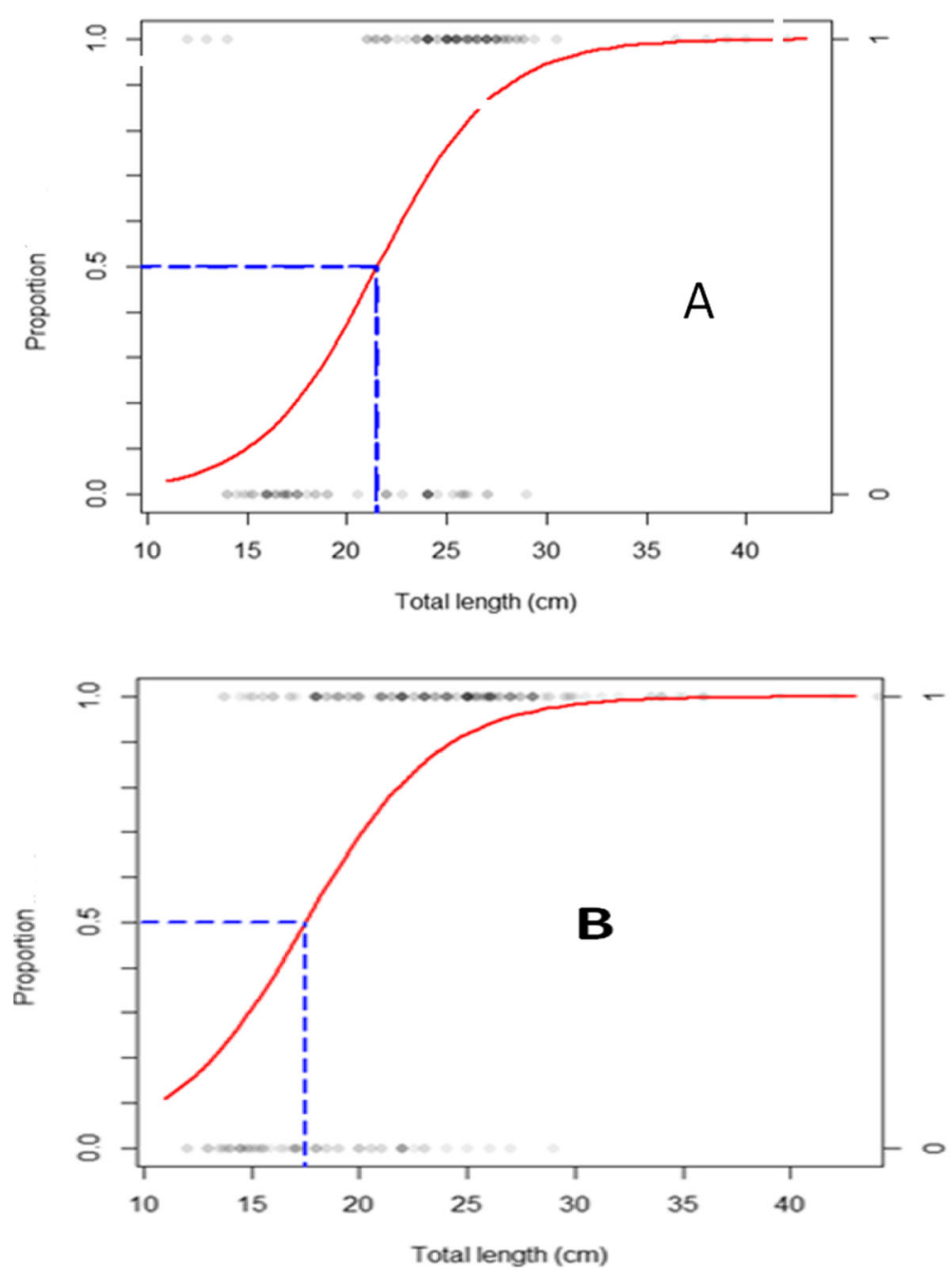

Fig. 6 Length at first sexual maturity $\left(L_{50}\right)$ of female (a) and male (b) C. carpio in Lake Hayq 


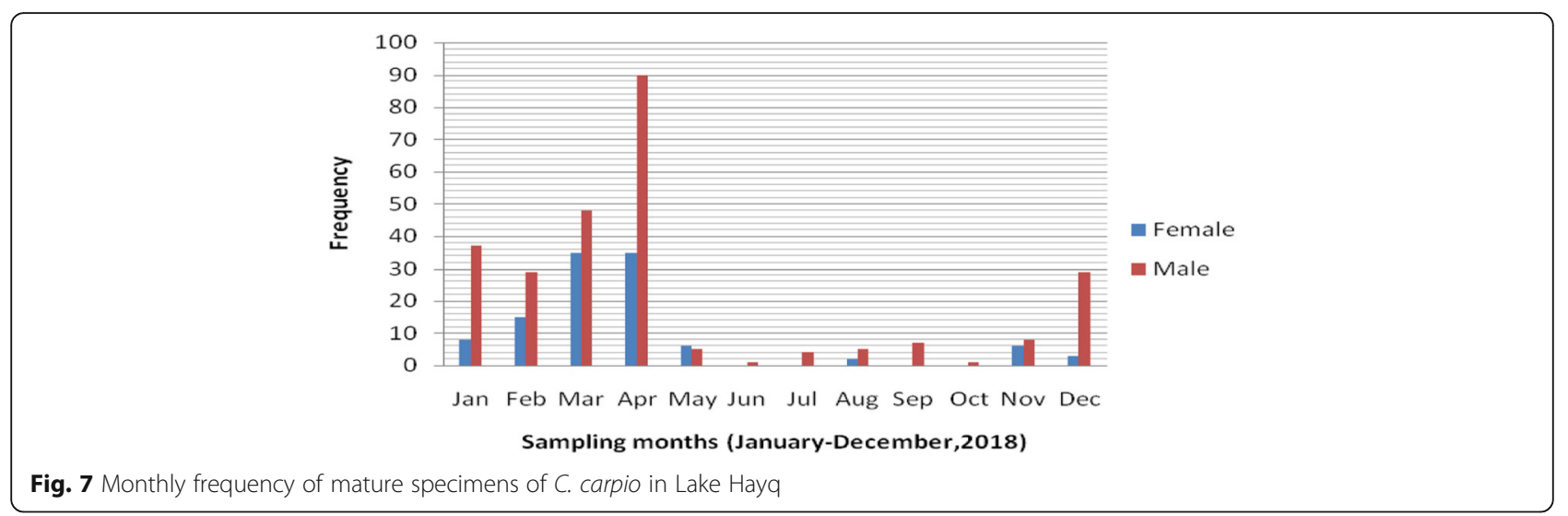

Length-weight relationships in fishes are an important tool in fish stock assessment to know the growth status and management of the fishes (Ujjania et al. 2012). The length-weight relationship of $C$. carpio in Lake Hayq was negative allometric growth with a " $b$ " value of 2.93 for females and 2.87 for males. These values were similar to 2.82 for C. carpio in Lake Ardibo for both sexes (Asnake 2010), 2.87 and 2.77 for female and male C. carpio in Foum El-Khanga Dam in Algeria (Sahtout et al. 2017), but different from 1.9 and 2.3 for female and male $C$. carpio in Lake Naivasha in Kenya (Aera et al. 2014) and 2.92 for C. carpio in Lake Amerti (Hailu 2013). These situations may be caused by several factors including the seasonal effect, habitat type, degree of stomach fullness, gonad maturity, sex, health, preservation techniques, food availability, differences in the observed length ranges, and fatness of the species as well as physical factors such as temperature and salinity (Wootton, 1998; Rahman et al. 2012; Hossain et al. 2016). The variations in " $b$ " values between males and females may depend on various factors such as the number of specimens examined, and the sampling season.

The FCF of females and males of C. carpio were 1.23 \pm 0.13 and $1.21 \pm 0.011$, respectively. These values were similar to $1.22 \pm 0.14$ for C. carpio in Amerti Reservoir
(Hailu, 2013), but different from 1.58 and 1.57 for female and male C. carpio in Damsa Dam Lake in Turkey (Mert and Bulut 2014), 1.57 for both sexes of C. carpio in Foum El-Khanga Dam in Algeria (Sahtout et al. 2017), and 1.39 and 1.27 for female and male C. carpio in Almus Dam Lake in Turkey (Karataş et al., 2007). These variations in $\mathrm{FCF}$ of $C$. carpio in different water bodies could be based on the difference in age, sex, season, stage of maturity, the fullness of gut, the type of food consumed, the amount of fat reserve, and the degree of muscular development (Pauker and Coot, 2004; Hossain et al. 2013).

The sex ratio (F:M) in this study was $1.3: 1$, and there was a significant deviation from hypothetical female to male ratio $(1: 1)$. The result of this study disagrees with Hailu (2013) that has reported nonsignificant variation (1.15:1) female to male ratio in Amerti Reservoir. However, this result agrees with the report (1.53:1) female to male ratio in Damsa Dam Lake in Turkey (Mert and Bulut 2014).

In the present study, the size at first sexual maturity of C. carpio was $17.5 \mathrm{~cm}$ for males and $21.5 \mathrm{~cm}$ for females. These values were similar to 15.8 and 22.5 for male and female C. carpio in Sidi Saad Reservoir in Tunisia (Hajlaoui et al. 2016). But these

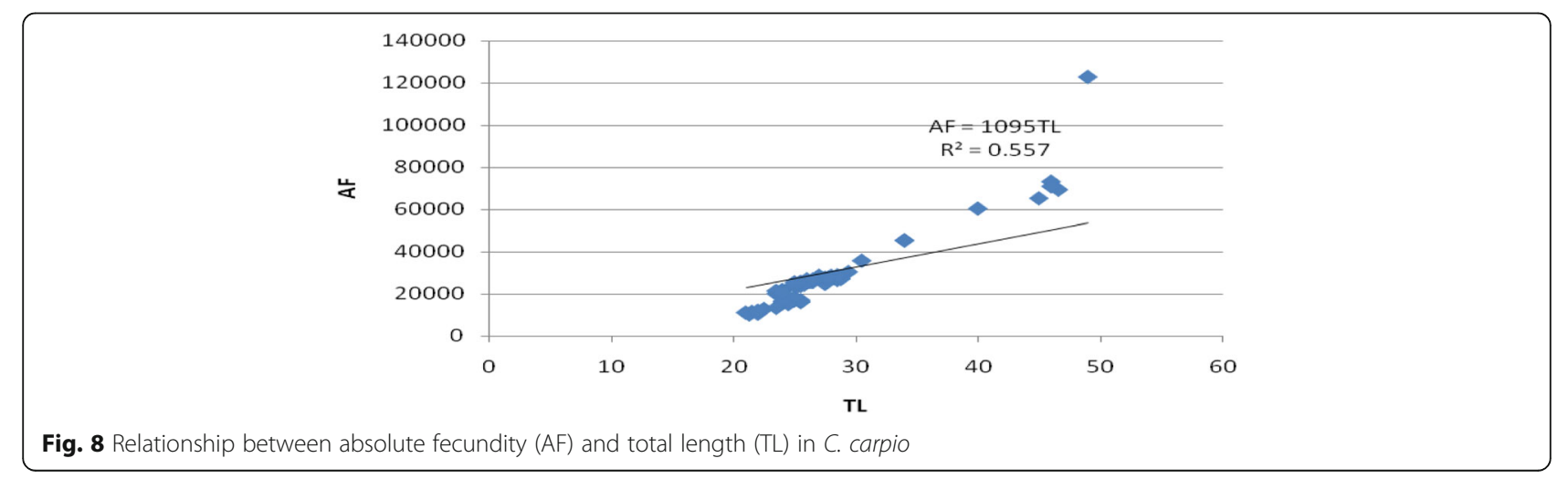




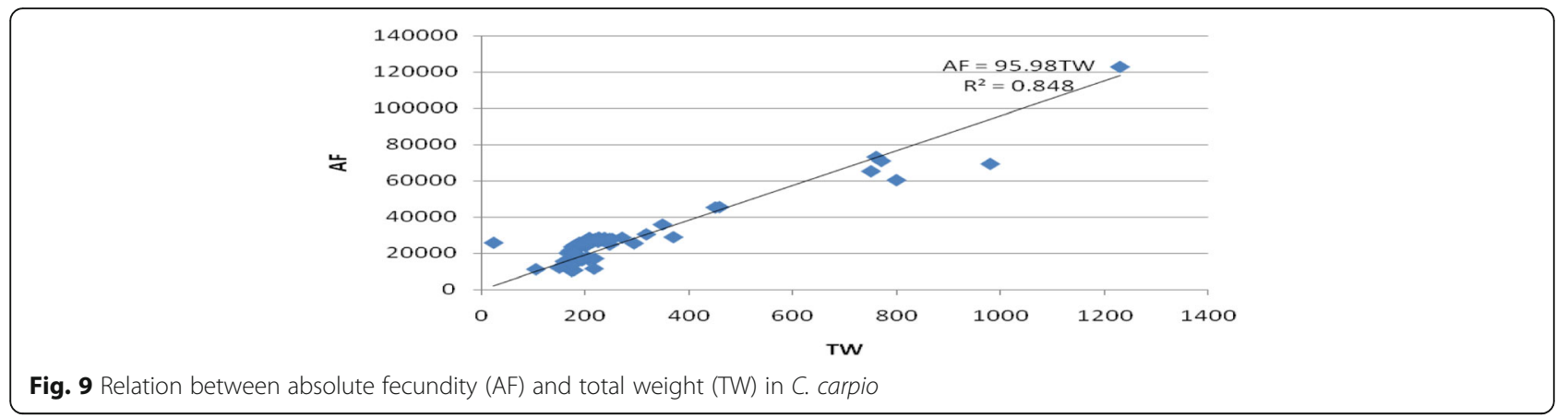

values were different from $27 \mathrm{~cm}$ and $28.3 \mathrm{~cm}$ for male and female C. carpio in Amerti Reservoir (Hailu 2013), $27 \mathrm{~cm}$ and $28.7 \mathrm{~cm}$ for male and female $C$. carpio in Lake Ziway (Abera et al. 2015), and 34 and $42 \mathrm{~cm}$ for male and female C. carpio in Lake Naivasha in Kenya (Oyugi 2012 ).

Knowledge on the fecundity of fish is important to examine the potential of its stocks, life history, practical culture, and actual management of the fishery (Islam et al. 2012). The range and the mean fecundity of $C$. carpio in Lake were 10,316-122,600 and $28100 \pm 17462$, respectively. These values were greater than the absolute fecundity range of 1610-99,737 for C. carpio in Lake Ardibo (Asnake 2010). However, the fecundity of $C$. carpio of Lake Hayq was lower than most water bodies of Ethiopia; it is less than a range of 36955318584 and mean of $170937 \pm 1308$ fecundity recorded for C. carpio in Amerti Reservoir (Hailu 2013) and a range of 75645-356745 and mean of 210538 for C. carpio in Lake Ziway (Lemma et al. 2015). Fecundity of $C$. carpio depends on body size and produce between 500,000 and 3 million eggs per spawning (Smith 2004). Thus, the reproductive potential of C. carpio is exceptional as they mature early, are highly fecund, increase reproductive effort with age over their life span, and reproduce at least once each year when conditions are appropriate for survival of larvae. The lower absolute fecundity in Lake Hayq could be due to the smaller size of fish compared to the C. carpio in Amerti and Lake Ziway.

Appropriate identification of the maturity status of fishes is a fundamental strategy for the appropriate management of exploited stocks in the fishery and is commonly used tools by fisheries' biologists and managers (Rahman et al. 2018). The monthly average GIS values of males and females were higher from February to April and were highest in April (Fig. 11). The lowest and highest GSI values were 1.1 and 4 for males and 3.5 and 10 for female C. carpio. The GIS values of females were higher than those of males due to the higher gonad weight of females. The observed higher values of GSI of both males and females between February and April and the highest values in April might be associated with higher atmospheric and water temperature values of 26 and $23{ }^{\circ} \mathrm{C}$, respectively. Rainfall availability might also contribute for more food (planktons, macrophytes, and detritus) together with temperature, and triggers the spawning of $C$. carpio in Lake Hayq. The mean monthly average water temperature of Lake Hayq was $23^{\circ} \mathrm{C}$, and better rainfall was recorded during the spawning months. In agreement with the current study, peak breeding season was recorded in Amerti Reservoir (Hailu 2013) and Lake Ziway (Abera et al. 2015) when water temperature becomes higher and rainfall is available. C. carpio in Lake Hayq has more than one spawning season similar to Amerti Reservoir (Hailu 2013),

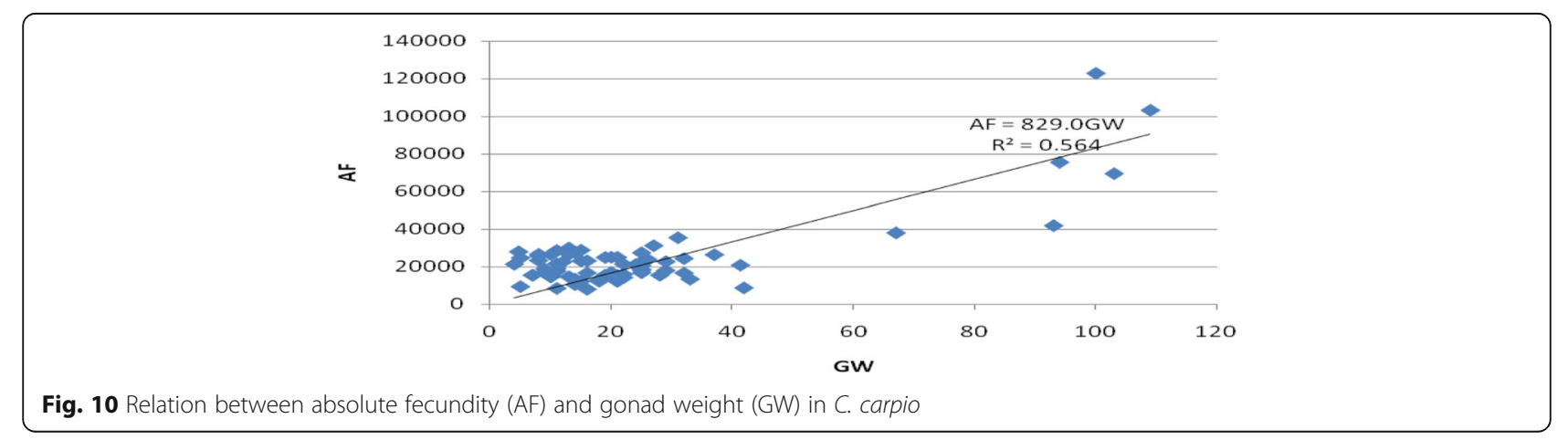




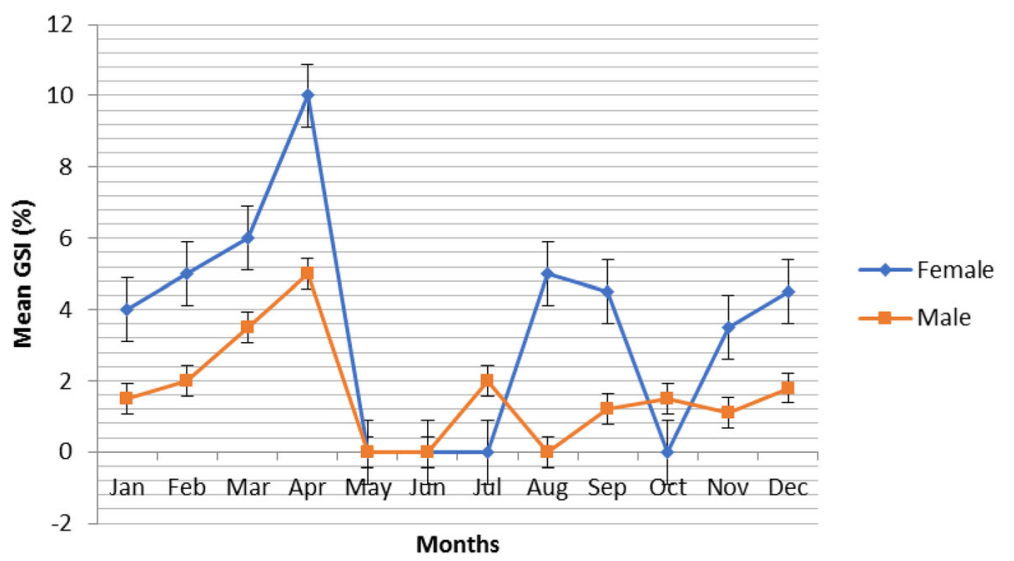

Fig. 11 Mean monthly gonadosomatic index (GSI) of C. carpio in Lake Hayq

Lake Ziway (Abera et al. 2015), and Lake Naivasha in Kenya (Oyugi, 2012). This might be related to the thermally stable warm environment and unlimited food resources (Muchiri et al. 1995). The mean monthly surface water temperature that ranged from 21.1 to $25.1{ }^{\circ} \mathrm{C}$ during the study period appears to favor year-round spawning of common carp in Lake Hayq.

\section{Conclusion and recommendation}

The growth and condition of common carp in Lake Hayq were good. The absolute fecundity of common carp in Lake Hayq was lower compared to other Ethiopian and African water bodies which could be due to smaller size of fishes used for fecundity analysis. The $L_{50}$ values of common carp were smaller $(17.5$ and $21.5 \mathrm{~cm}$ for male and female) which might be associated with illegal fishing activities, and narrow-sized gillnets of mesh size of 4-6 cm. Hence, the mesh size of the gillnets should be regulated at least to $8 \mathrm{~cm}$ which is the national standard. Furthermore, common carp have extended spawning seasons in Lake Hayq (February-April) with peak spawning in April. Therefore, these intense spawning months should be used for closing seasons (no fishing activities). Thus restricted gillnet use and closed season practices could bring better recruitment and better fish size. Long-term monitoring on reproduction potential, spawning season, and population status of common carp should be done for sustainable fishery utilization of Lake Hayq.

\section{Acknowledgements}

The authors would like to acknowledge Addis Ababa University, Ministry of Water, Irrigation, and Electricity, Haik Agricultural Research Sub-Center, for their financial and logistic support. We would also like to extend our gratitude to fishermen of Lake Hayq, specially Fiseha Woldemariam and Seid Abebe, for their unreserved support during fish sample collection and Kidane Aragaw for his support in the data analysis especially logistic regression analysis using R software.

\section{Declaration}

Not applicable
Authors' contributions

$T A$, the corresponding author, has prepared the report from the collected data where us GA, MS, FT, and DE are co-authors who have edited the paper. The authors read and approved the final manuscript.

\section{Authors' information}

TA is currently a PhD student in Addis Ababa University.

The co-authors, GA and MS, are professors, and FT is an associate professor working in Addis Ababa University department of Zoological sciences. They have published many articles in fisheries and Aquatic Sciences and have advised MSc and PhD students. The last co-author, DE, is a senior and energetic researcher in fishery and aquaculture areas. He is a PhD holder and working in IGAD at senior fishery expert.

\section{Funding}

Addis Ababa University and Ministry of Water, Irrigation, and Electricity have granted us 2000 USD for data collection for this research. The funding organizations have commented on the work for the betterment of the paper.

Availability of data and materials

Data sharing is not applicable.

Ethics approval and consent to participate

Not applicable, since there is no ethical approval process for fishery data in Ethiopia.

\section{Consent for publication}

Not applicable

\section{Competing interests}

The authors declare that they have no competing interests.

\section{Author details}

'Department of Zoological Sciences, Addis Ababa University, Addis Ababa, Ethiopia. ${ }^{2}$ Intergovernmental Authorities on Development (IGAD), Djibouti City, Djibouti.

Received: 16 September 2019 Accepted: 31 May 2020

Published online: 30 June 2020

\section{References}

Abera L, Getahun A, Lemma B. Some aspects of reproductive biology of the common carp (Cyprinus Carpio Linnaeus, 1758) in Lake Ziway, Ethiopia. Global J Agric Res Rev. 2015;3:151-7.

Aera NC, Migiro EK, Yasindi A, Outa N. Length-weight relationship and condition factor of common carp, (Cyprinus carpio) in Lake Naivasha, Kenya. Int I Curr Res. 2014;6:8286-96.

Asnake W. Fish resource potential and some biological aspect of Oreochromis niloticus and Cyprinus carpio in Lake Ardibo, Northern Ethiopia. MSc Thesis, 
College of Agricultural and Environmental Science. Bahir Dar: Bahir Dar University; 2010.

Bagenal TB, Braum E. Methods for assessment of fish production in freshwaters. London: Blackwell Scientific Publications; 1987.

Bagenal TB, Tesch FW. Age and growth. In: Bagenal TB, editor. Methods for assessment of fish production in freshwaters. Handbook no.3, England. Oxford: Blackwell; 1978. p. 101-136.

Balon EK. Reproductive guilds of fishes: a proposal and definition. J Fish Res Board Can. 1975;32:821-64.

Banarescu P, Coad B W. Cyprinids of Eurasia. In: Winfield, IJ, Nelson JS, editors: Cyprinid fishes: systematics, biology, and exploitation., Chapman and Hall, London 1991. p127-155.

Cochrane KL. A fishery manager's guidebook: management measures and their application. In: FAO fisheries technical paper. No. 424. Rome: FAO; 2002. p. 231.

Demlie M, Ayenew T, Stefan W. Comprehensive hydrological and hydrogeological study of topographically closed lakes in highland Ethiopia: the case of Hayq and Ardibo Lakes. J Hydrol. 2007;339:145-58.

Echeverria TW. Thirty-four species of California rockfishes: maturity and seasonality of reproduction. US Fish Bull. 1987;85:229-50.

FAO. Fish state plus: Universal software for fishery statistical time series (available at www.fao.org/fi/statist/fisoft/fishplus.asp). 2013.

FAO (Food and Agricultural Organization). Aquaculture production statistics 1986-1996. FAO fish. Circ, 815, Rev. 9. 1997.

Fetahi T, Michael S, Mengistou S, Simone L. Food web structure and trophic interactions of the tropical highland Lake Hayq. Ethiopia Ecol Model. 2011; 222:804-13.

Forester TS, Lawrence JM. Effects of grass carp and carp on populations of bluegill and largemouth bass in ponds. Trans Am Fish Soc. 1978;107:172-5.

Getahun A. The freshwater fishes of Ethiopia, diversity, and utilization. Addis Ababa: View Graphics and Printing Plc; 2017.

Golubtsov AS, Darkov AA. A review of fish diversity in the main drainage systems of Ethiopia based on the data obtained by 2008. In: Pavlov DS, Dgebudaze, YuYu, Darkov AA, Golubtsov AS, Mina MV, editors. Ecological and faunistic studies in Ethiopia, "Proceedings of Jubilee Meeting Joint Ethio-Russian Biological Expedition: 20 years of scientific cooperation". Moscow: KMK Scientific Press Ltd; 2008. p. 69-102.

Hailu M. Reproductive aspects of common carp (Cyprinus Carpio L, 1758) in Amerti reservoir, Ethiopia. J Ecol Nat Environ. 2013;5:260-4.

Hajlaoui W, Missaoui S. Reproductive biology of the common carp, Cyprinus carpio communis, in Sidi Saad reservoir (Central Tunisia). Bull Soc Zool Fr. 2016:141:25-39.

Hossain MY, Hossen MA, Islam MM, Pramanik MNU, Nawer F, Paul AK, et al. Biometric indices and size at first sexual maturity of eight alien fish species from Bangladesh. Egypt J Aquatic Res. 2016;42:331-9.

Hossain MY, Hossen MA, Islam MS, Jasmine S, Nawer F, Rahman MM. Reproductive biology of Pethia ticto (Cyprinidae) from the Gorai River (SW Bangladesh). J Appl Ichthyol. 2017;33:1007-14.

Hossain MY, Ohtomi J. Reproductive biology of the southern rough shrimp Trachysalambria curvirostris (Penaeidae) in Kagoshima Bay, southern Japan. J Crustac Biol. 2008;28:607-12.

Hossain MY, Rahman MM, Abdallah EM, Ohtomi J. Biometric relationships of the pool barb Puntius sophore (Hamilton 1822) (Cyprinidae) from three major rivers of Bangladesh. Sains Malaysiana. 2013;22:1571-80

Islam MR, Sultana N, Hossain MB, Mondal S. Estimation of fecundity and gonadosomatic index (GSI) of gangetic whiting, Sillaginopsis panijus (Hamilton, 1822) from the Meghna River Estuary, Bangladesh. World Appl Sci J. 2012;17:1253-60.

Karataş M, Çiçek E, Başusta A, Başusta N. Age, growth, and mortality of common carp (Cyprinus Carpio Linneaus, 1758) population in Almus dam Lake (TokatTurkey). J Appl Biol Sci. 2007;1:81-5.

Khatun D, Hossain MY, Nawer F, Mostafa AA, Al-Askar AA. Reproduction of Eutropiichthys vacha (Schilbeidae) in the Ganges River (NW Bangladesh) with special reference to the potential influence of climate variability. Environ Sci Pollut Res. 2019:26:10800-15.

Koehn JD. Carp (Cyprinus carpio) as a powerful invader in Australian waterways. Freshw Biol. 2004:49:882-94.

Lemma A, Abebe G, Brook L. Some Aspects of Reproductive Biology of the common carp (Cyprinus Carpio Linnaeus, 1758) in Lake Ziway, Ethiopia. Global Journal of Agricultural Research and Reviews. 2015;3:151-157.
Mert R, Bulut S. Some biological properties of carp (Cyprinus carpio L., 1758) introduced into Damsa Dam Lake, Cappadocia Region, Turkey. Pakistan J Zool. 2014;46:337-46.

Muchiri SM, Hart BJ, Harper MD. The persistence of two introduced tilapia species in Lake Naivasha, Kenya in the face of environmental variability and fishing pressure. In: Pitcher TJ, Hart PJB, editors. The impact of species changes in African lakes: Chapman \& Hall; 1995. p. 299-320.

Oyugi OD. Ecological impacts of common carp (Cyprinus Carpio L. 1758) (Pisces: Cyprinidae) on naturalised fish species in Lake Naivasha, Kenya. PhD dissertation. Kenya: University of Nairobi; 2012.

Pauker C, Coot RSR. Factors affecting the condition of Flanmelmout suckers in Colorado River, grand canyon, Arizona. North Am J Fish Manag. 2004;24:64853.

Rahman MM, Hossain MY, Jewel MAS, Rahman MM, Jasmine S, Abdallah EM, Ohtomi J. Population structure, length-weight, and length-length relationships, and condition-and form-factors of the Pool barb Puntius sophore (Hamilton, 1822) (Cyprinidae) from the Chalan Beel, North-Central Bangladesh. Sains Malaysiana. 2012;41:795-802.

Rahman MM, Hossain MY, Jo Q, Kim SK, Ohtomi J, Meyer C. Ontogenetic shift in dietary preference and low dietary overlap in rohu (Labeo rohita) and common carp (Cyprinus carpio) in semi-intensive polyculture ponds. Ichthyol Res. 2009;56.

Rahman MM, Hossain MY, Tumpa AS, Hossain MI, Billah MM, Ohtomi J. Size at sexual maturity and fecundity of the mola carplet, Amblypharyngodon mola (Hamilton 1822) (Cyprinidae) in the Ganges River, Bangladesh. Zool Ecol. 2018;28:429-36.

Rahman MM, Jo Q, Gong YG, Miller SA, Hossain MY. A comparative study of common carp (Cyprinus carpio L.) and calbasu (Labeo calbasu Hamilton) on bottom soil resuspension, water quality, nutrient accumulations, food intake, and growth of fish in simulated rohu (Labeo rohita Hamilton) ponds. Aquaculture. 2008;285:78-83.

Ricker WE. Computational and interpretation of biological statistics of fish populations Bulletin of the Fisheries Research Board of Canada; 1975.

Sahtout F, Boualleg C, Khelifi N, Kaouachi N, Boufekane B, Brahmia S, et al. Study of some biological parameters of Cyprinus carpio from Foum El-Khanga dam, souk-Ahras. Algeria. AACL Bioflux. 2017;10:663-74.

Smith BB. Common carp (Cyprinus carpio L.1758): Spawning dynamics and early growth in lower River Murray. PhD dissertation, School of Earth and Environmental Sciences, University of Adeilaide, Austrialia. 2004.

Temesgen M. Status and trends of fish and fisheries in a tropical rift valley lake, Lake Langeno, Ethiopia. PhD dissertation, Department of Zoological Sciences. Addis Ababa: Addis Ababa University; 2017.

Troca DFA, Vieira JP. Potencial invasor dos Peixes Não Nativos Cultivados Na Região Costeira do Rio Grande Do Sul, Brasil. Bol Inst Pesca. 2012;38:109-20.

Ujjania NC, Kohli MPS, Sharma LL. Length-weight relationship and condition factors of Indian major carps (Catla catla, Labeo rohita, and Cirrhinus mrigala) in Mahi Bajaj Sagar, India. Res J Biol. 2012;2:30-6.

Weber M, Brown M. Effects of common carp on aquatic ecosystems 80 years after "carp as a dominant": ecological insights for fisheries management. Rev Fish Sci. 2009:17:524-37.

Wootton RJ. Ecology of teleost fishes. 2nd ed. London: Kluwer Academic Publishers; 1998

Wudneh T. Biology and management of fish stocks in Bahir Dar Gulf, Lake Tana, Ethiopia. PhD dissertation. Wageningen: Wageningen Agricultural University; 1998.

\section{Publisher's Note}

Springer Nature remains neutral with regard to jurisdictional claims in published maps and institutional affiliations. 